\title{
REGLAS ADMINISTRATIVAS. EXAMEN RESPECTO A SU ALCANCE JURÍDICO ${ }^{1}$
}

\section{Emilio Margáin Manautou²}

Sumario: I. Introducción.II. ¿Qué es la regla Administrativa? III.Postura del CFF IV.Ejemplos V. Criterios de los contribuyentes respecto al alcance de las reglas administrativas versus interpretación judicial VI.Conclusiones

Resumen. En el presente documento se analiza el alcance jurídico de la regla administrativa en México, por medio de la contrastación del apecto teórico del concepto con lo dispuesto en la legislación federal a la luz de la interpretación realizada por el Poder Judicial.

Palabras clave: regla administrativa ,alcance jurídico, interpretación judicial

Abstract.This document analyzes the legal scope of the administrative rule in Mexico, by contrasting the theoretical aspect of the concept with the provisions of federal legislation in light of the interpretation made by the Judicial Power

Keywords: administrative rule, legal scope, judicial interpretation

1 Conferencia impartida el día 17 de noviembre de 2006, en el Aula Magna Roberto Reynoso Dávila, con motivo del LIII Aniversario del Departamento de Derecho de la Universidad de Sonora. Las recientes actuaciones de las autoridades fiscales rescatan la relevancia del tema y su necesaria divulgación por BIOLEX a la vanguardia en el planteamiento de soluciones a la problemática jurídica de los contribuyentes derivada de los excesos de las autoridades fiscales.

2 Distinguido Catedrático Emérito de Derecho Fiscal y Administrativo de la Universidad Nacional Autónoma de México y de otras Universidades Públicas y Privadas del País y del extranjero. Doctor Honoris causa por CENIJUR Centro de Investigación Jurídica Puebla. Reconocido Profesional de los Foros Jurídicos Nacionales y Locales en el ámbito Administrativo y Fiscal. Autor de mas de 20 obras en la materia actualizadas cada año, tales como: "Introducción al Estudio del Derecho Tributario", "Introducción al Estudio del Derecho Administrativo, "De lo Contencioso Administrativo de Anulación o de llegitimidad, Política Fiscal, Recursos Administrativos entre otras. "Distinguido Miembro Invitado Permanente" de la Academia de Derecho Administrativo" a partir de la entrada en vigor(1991) de la Ley 4 que regula orgánicamente la vida académica de la Universidad de Sonora. 


\section{Introducción}

Entiéndase por Regla una breve narración de la cosa, no para que la misma regla forme derecho, sino por el contrario, la regla debe emanar de un derecho previamente establecido. La Regla, pues, debe ser suscinta narración de una cosa, o como dice Sabino, un compendio de ella cuya regla deja de llenar ese objeto desde el momento en que adolece de algún defecto ${ }^{3}$ o, en estos términos, la regla administrativa nos debe de aclarar lo que dice una disposición pero sin excederse del contenido de las palabras que empleó el legislador, sea el Congreso de la Unión o el Poder Legislativo, nunca ir más allá del espíritu que contienen la disposición que se interpreta por autoridad administrativa. Sin embargo ha surgido la inquietud respecto al alcance jurídico que tienen las reglas administrativas que en materia tributaria y en materia administrativa se han expedido por entes dependientes de Secretarías de Estado, visto su uso extraordinario, por la Secretaría de Hacienda y Crédito Público y, por la entonces, Secretaría de Industria y Comercio, en las que se aprecia que en ocasiones atenúan el impacto de las novedades aprobadas por el Congreso de la Unión, en otras se utilizan para aclarar lo dispuesto en esas novedades, o bien para colmar lagunas o subsanar errores existentes en las leyes o para crear nuevas obligaciones o requisitos no previstos en ellas, o en ocasiones, lo cual es grave, porque el legislador delega esta facultad en la dependencia correspondiente obien en un órgano desconcentrado de la misma, lo que ha dado origen, en estos últimos supuestos, a que se diga que existe un legislador no provisto en el artículo 71 de la Constitución Política de los Estados Unidos Mexicanos, que señala quien tiene el derecho para iniciar leyes o decretos ante las Cámaras que constituyen el Congreso de la Unión.

Bien puede sostenerse que las reglas administrativas surgieron en la entonces Secretaría de Industria y Comercio, hoy de Economía, pero tomando fuerza su

${ }^{3}$ Cejudo y Ormaechea Ignacio, Reglas del Derecho- en español y latín-, obra escrita a principios del Siglo XX. 
expedición por la Secretaría de Hacienda y Crédito Publico y, después, a partir de la creación como órgano desconcentrado, por el Servicio de Administración Tributaria.

Cuando se expidió la Ley de Inversiones Extranjeras, en la época del Presidente Luis Echeverría Álvarez, surgió con ella la intranquilidad a la inversión extranjera, expidiéndose meses después de su vigencia unas cuantas reglas que dieron origen a reuniones muy concurridas, pues en ellas se advertía que la autoridad administrativa atenuaba el contenido de la Ley antes mencionada, y hoy, anualmente, se expide por el Jefe del Servicio de Administración Tributaria la Resolución conteniendo elevado número de reglas administrativas, que, inclusive se modifican o se establecen nuevas al poco tiempo de su vigencia, originando, en ocasiones, la creación de problemas que ocasionan un fuerte daño a la recaudación tributaria y que al mes o dos, conociéndose por las autoridades del fisco el prejuicio que le están ocasionando los deroga o ante la protesta masiva de algunas de ellas, tanto por parte de los Colegios de Contadores Públicos como de los organismos empresariales, se difiere su vigencia buscando con ello modificarlas atendiendo a las objeciones expuestas o para dar tiempo a su mejor entendimiento.

\section{¿Qué es la regla Administrativa?}

Por la regla administrativa debemos entender la interpretación que se da por las autoridades administrativas a disposiciones legales para el mejor conocimiento de lo dispuesto en un ordenamiento, lo cual se observa en buen número de las que contiene la Resolución de reglas generales en materia tributaria que año con año expide el Fisco Federal, aun cuando también buen número de ellas tienen por objeto atenuar el impacto de novedades fiscales por los efectos pernicioso que se observan al entrar en vigor, o bien integrar la ley por las omisiones o errores que en ellas se conocen al ser objeto de examen por los contribuyentes o bien 
introducir novedades que no contienen las leyes que son nuevas o que se modifican, tales como nuevos requisitos u obligaciones no previstos en ellas.

\section{Veamos ahora que nos dice al respecto el Código Fiscal de la Federación.}

En el penúltimo párrafo de la fracción II del artículo 39, se expresa que "asimismo, las autoridades fiscales darán a conocer a los contribuyentes, a través de los medios de difusión que se señalen en reglas de carácter general, los criterios de carácter interno que emitan para el debido cumplimiento de las disposiciones fiscales, salvo aquellos que, a juicio de la propia autoridad, tengan el carácter de confidenciales sin que para ello nazcan obligaciones para los particulares y únicamente derivaran derechos de los mismos cuando se publiquen en el Diario Oficial de la Federación", esto es, no pueden surgir de dichos criterios nuevas obligaciones para los particulares.

El artículo 35 de ese mismo ordenamiento establece que "Los funcionarios fiscales facultados debidamente podrán dar a conocer a las diversas dependencias el criterio que deberán seguir en cuenta a la aplicación de las disposiciones fiscales, sin que por ello nazcan obligaciones para los particulares y únicamente derivaran derechos de los mismos cuando se publiquen en el Diario Oficial de la Federación".

Por criterio debemos entender la norma o regla para adecuar la verdad, pero no para alterarlo.

Pero cuando el legislador delega ya no en el Ejecutivo Federal sino en el Servicio de Administración Tributaria, que es un órgano desconcentrado de la Secretaría de Hacienda y Crédito Público, surge un problema de inconstitucionalidad por delegar el Congreso de la Union facultades que a él le corresponde ejercer. 


\section{Ejemplos:}

a) El artículo 31, fracción I, primer párrafo, de la Ley del Impuesto sobre la Renta, establece que "Las deducciones autorizadas en este Título deberán reunir los siguientes requisitos $I$. Ser estrictamente indispensable para los fines de la actividad del contribuyente, salvo que se de donativos no onerosos ni remunerativos, que satisfagan los requisitos previstos en esta Ley y en las reglar generales que para el efecto establezca el Servicio de Administración Tributaria y que se otorguen en los siguientes casos:...".

b) La segunda parte del penúltimo párrafo de la fracción IX del artículo 29-A del Código Fiscal de la Federación, nos dice: "Dichos contribuyentes quedarán liberados de esta obligación cuando las operaciones con el público en general se realicen con un monedero electrónico que reúna los requisitos de control que para tal efecto establezca el Servicio de Administración Tributaria mediante las reglas de carácter general."

c) La segunda parte u oración del penúltimo párrafo de la fracción II del artículo 19 de la Ley del Impuesto Especial sobre Producción y Servicios, nos dice: "Asimismo, los citados contribuyentes deberán proporcionar al Servicio de Administración Tributaria en forma trimestral, en los meses de abril, julio, octubre y enero del año que corresponda, la relación de las personas a las que en el trimestre anterior al que se declare les hubiese trasladado el impuesto especial sobre la producción y servicios en forma expresa y por separado en los términos de esta fracción, asi como el monto del impuesto trasladado en dichas operaciones y la información y documentación que mediante reglas de carácter general señale el Servicio de Administración Tributaria". Se impone una obligación que deberá precisar el SAT a través de las reglas generales.

Pero lo anterior parece encontrar el respaldo en la Ley Federal de los Derechos del Contribuyente, en el último párrafo de su artículo $6^{\circ}$., que nos dice: 
"Art. $6^{\circ} \ldots$

Los contribuyentes que se apeguen a los términos establecidos en los criterios emitidos por las autoridades fiscales, que se publiquen en el Diario Oficial de la Federación, quedaran exentos de responsabilidad fiscal."

Conforme a lo transcrito si un criterio que se convierte en regla administrativa viene a integrar a la ley en perjuicio de los contribuyentes o a introducir novedades que no contiene ella en beneficio del Fisco Federal, como nuevas obligaciones o requisitos, de no respetarse el contenido ilegal de dicho criterio ¿se está incurriendo en una responsabilidad fiscal?

La Ley antes citada, que se supone se expide para proteger los derechos de los contribuyentes de excesos de las autoridades fiscales, viene a empeorar su situación fiscal al exigir el cumplimiento de las reglas administrativas que resultan ilegales, al pretender que se deben de acatar interpretaciones erróneas para no incurrir en responsabilidad fiscal. Vaya forma de proteger los derechos de los contribuyentes.

Criterios de los contribuyentes respecto al alcance de las reglas administrativas.

Son diversas las tesis que han sustentado tanto el Tribunal Federal de Justicia Fiscal y Administrativa, a través de sus Salas, como los Tribunales Colegiados de Circuito, y el Pleno y Salas de la Suprema Corte de Justicia de la Nación.

a) En el Juicio de nulidad número 12164/01-17-10-3, de la Décima Sala Regional Metropolitana del TFJFA, en sentencia de fecha 21 de enero de 2002, en el CONSIDERANDO CUARTO, resolvió:

"a juicio de los suscritos Magistrados el agravio hecho valer por la demandante es fundado, de acuerdo a los razonamientos expresados por el actor, en el sentido de que la autoridad la está sancionando por una obligación que no se encuentra prevista en la ley, sino en reglas de carácter general, las cuales no pueden imponer cargas a los 
particulares, sino por el contrario crean derechos, toda vez que la identificación fiscal de su cliente a favor de quien expide las facturas infringiendo lo dispuesto por el artículo 29 del Código Fiscal de la Federación, el cual para una mejor comprensión a continuación se transcribe":

"Articulo 29.- cuando las leyes fiscales establezcan la obligación de expedir comprobantes por las actividades que se realicen, dichos comprobantes deberán reunir los requisitos que señala el artículo 29A de este Código. Las personas que adquieran bienes o usen servicios deberán solicitar el comprobante respectivo.

Asimismo, quienes expidan los comprobantes fiscales referidos deberán de asegurarse de que el nombre, denominación o razón social de la persona a favor de quien se expidan los comprobantes correspondan con el documento con el que acrediten la clave del registro federal de contribuyentes que se asienta en dichos comprobantes. La Secretaría de Hacienda y Crédito Publico mediante disposiciones de carácter general, podrá establecer facilidades para la identificación del adquiriente".

El articulo antes transcrito permite apreciar que, cuando las leyes fiscales establezcan la obligación de expedir comprobantes fiscales, dichos comprobantes deberán reunir los requisitos que señala el artículo 29-A del Código Fiscal de la Federación; asimismo quienes los expidan deberán de asegurarse que el nombre, denominación o razón social de la persona a favor de quien se expidan los comprobantes correspondan con el documento con el que acrediten la clave del registro federal de contribuyentes que se asienta en dichos comprobantes; por lo que en la especie, en ninguna parte del artículo en comento se establece la obligación de conservar las copias fotostáticas de las cedulas de identificación fiscal delos clientes, sino que se encuentra prevista en una Regla de carácter general, que de ninguna manera puede imponer obligaciones a los particulares, la cual a continuación se transcribe: 
2.4.10. Para efectos del artículo 29, cuarto párrafo del código, la obligación de cerciorarse de que los datos de la persona a cuyo favor se expide un comprobante fiscal, se tendrá por cumplida cuando se conserve copia de la cedula de identificación fiscal de la persona a cuyo favor de expida, así como en los supuestos previstos en la regla 2.4.12. Tratándose de la prestación de servicios en restaurantes, esta obligación se tendrá por satisfecha cuando en el anverso del comprobante que conserve el establecimiento, se anote el número de folio de la cedula de identificación fiscal proporcionada por el cliente. ...".

\section{(Énfasis añadido)}

La Regla transcrita considera que se cumple con la obligación establecida en el artículo 29, cuarto párrafo, al cerciorarse el contribuyente que los datos de la persona a cuyo favor se expide son ciertos y se tendrá por cumplida cuando se conserve copia de la cedula de identificación fiscal; es decir, es en la Resolución Miscelánea en donde se establece una obligación más para que el establecimiento, en virtud de que determina un requisito que no se encuentra contenido en la ley, lo que contraviene el principio de certidumbre que toda norma jurídica debe de contener.

Ello es así, en virtud de que, atendiendo a la naturaleza de las Resoluciones Misceláneas Fiscales, éstas no pueden estar por encima de la ley, en virtud de que son disposiciones emitidas por autoridad administrativa en las que la autoridad fiscal debe indicar como deben de conducirse los contribuyentes o como deben aplicar los ordenamientos legales; pero de ninguna manera pueden establecer más requisitos que los contenidos en la norma, toda vez que al establecer el requisito de que se guarde copia de la cedula de identificación fiscal, está excediendo con ello el contenido del cuarto párrafo del artículo 29 del Código Fiscal de la Federación, en virtud de que la autorización prevista en el artículo primeramente citado no implica o faculta la creación de una hipótesis diversa considerar que se cumplen con la obligación de expedir comprobantes con requisitos fiscales. 
Encuentra sustento lo anterior en la tesis aislada en la parte que nos interesa, del Primer Tribunal Colegiado en Materia Administrativa del Primer Circuito, publicado en el Semanario Judicial de la Federación y su gaceta, mayo de 2001, página 1180 que a continuación transcribe:

Novena Época

Instancia: PRIMER TRIBUNAL COLEGIADO EN MATERIA ADMINISTRATIVA DEL PRIMER CIRCUITO.

"MISCELÁNEA FISCAL REGLA 2.2.9. PARA EL EJERCICIO DEL AÑO 1997, ES INCONSTITUCIONAL PORQUE EXCEDE LO DISPUESTO POR EL ÁRTICULO 23, SEGUNDO PARRAFO, DEL CODIGO FISCAL DE LA FEDERACIÓN. Como la regla 2.2.9. Contenida en la miscelánea fiscal para el ejercicio de mil novecientos noventa y siete, publicada en el Diario Oficial de la Federación de veintiuno de marzo de mil novecientos noventa y siete, señala como condición de procedibilidad de la compensación pretenda el contribuyente deben corresponder al mismo ejercicio, establece un requisito no previsto por el artículo 23, segundo párrafo, del Código Fiscal de la Federación, excediendo con ello la norma legal que debe constituir su justificación y medida, en virtud de que la autorización prevista en el citado artículo 23 a favor de la Secretaría de Hacienda y Crédito Publico no implica o faculta la creación de hipótesis diversas para la procedencia de la compensación"

PRIMER TRIBUNAL COLEGIADO EN MATERIA ADMINISTRATOIVA DEL PRIMER CIRCUITO.

Amparo directo 6021/99. Armando Gálvez Pérez Aragón. 6 de octubre de 2000. Unanimidad de votos. Ponente: Luis María Aguilar Montes. Secretaria: Verónica Nava Ramírez."

(Énfasis añadido) 
A mayor abundamiento, la resolución impugnada viola en prejuicio de la parte actora lo dispuesto por el artículo 35 del Código Fiscal de la Federación para dar a conocer diversas disposiciones en cuanto a la aplicación de las normas fiscales, sin que por ello nazcan obligaciones para los particulares ya que es de conocido derecho que sólo pueden derivar derechos cuando se publiquen en el Diario Oficial de la Federación. Por otra parte, la autoridad en resolución impugnada considero que la actora infringió lo dispuesto en el artículo 83, fracción VII, del Código Fiscal de la Federación el cual establece:

\section{CÓDIGO FISCAL DE LA FEDERACIÓN.}

"Artículo 83.- Son infracciones relacionadas con la obligación de llevar contabilidad, siempre que sean descubiertas en el ejercicio de las facultades de comprobación, las

siguientes:

VII. No expedir comprobante de sus actividades, cuando las disposiciones fiscales lo establezcan o expedirlos sin requisitos fiscales.

$\ldots$

Dicho precepto establece como infracción, no expedir los comprobantes con requisitos fiscales, supuesto jurídico en el cual no se ubica la parte actora, tomando en consideración que los artículos 29, cuatro párrafo, del Código Fiscal de la Federación, no establece la obligación de conservar copia fotostática (sic) de la cédula de identificación fiscal del adquirente, ya que es un requisito que no está contenido en la norma legal, por lo tanto mediante la determinación de la autoridad se infringe lo dispuesto por el artículo 16 Constitucional y 38 del Código Fiscal de la Federación, que obliga a las autoridades a fundar y motivar debidamente sus actos.

No pasa inadvertido para esta Juzgadora el razonamiento expuesto como defensa por parte de la autoridad, en el sentido de que el artículo 29, cuarto párrafo, establece que los comprobantes fiscales deben reunir los requisitos que establezcan las reglas de carácter general, dada la interpretación contraria a derecho que efectúa la autoridad, ya que la remisión se refiere a que la Secretaría de Hacienda y Crédito Público mediante disposiciones de carácter general podrá establecer facilidades para la identificación del adquirente, no así a los requisitos mismos que deben reunir estos últimos o que una obligación más para el comerciante contribuyente.

finalmente, al no existir la violación al precepto citado por la demandante en la 
resolución impugnada, es inconcuso que en la especie la resolución materia de la presente controversia se encuentra indebidamente fundada, lo que trae como consecuencia su nulidad lisa y llana, de conformidad con el artículo 238, fracción IV, del Código fiscal de la federación".

b) Sin embargo, el Pleno de la Suprema Corte de Justicia de la Nación aprobó, por cinco votos a favor por cuatro en contra, las siguientes tesis.

'REGLAS GENERALES ADMINISTRATIVAS. LA FACULTAD DEL CONGRESO DE LA UNIÓN PARA HABILITAR A LAS SECRETARÍAS DE ESTADO A FIN DE EXPEDIRLAS, NO CONSTITUYE UNA DELEGACIÓN DE FACULTADES LEGISLATIVAS. El hecho de que el Congreso de la Unión autorice a las Secretarías de Estado a emitir reglas técnico-operativas de observancia general en su ramo, no entraña una delegación de facultades, pues aquel órgano legislativo no se despoja de una facultad propia, lo que constituye una condición insalvable de todo acto delegatorio, sino que asigna directamente a un órgano de la administración pública federal, una tarea operativa para facilitar la aplicación de una ley específica dentro de su campo de acción. Lo anterior se justifica en la medida en que el Poder Legislativo no suele ocuparse de esos detalles técnico-operativos que surgen en el funcionamiento de la administración pública; de ahí que resulte apropiado que los secretarios de Estado, como integrantes de la administración pública federal y conforme a los dispuesto en el artículo 90 de la Constitución Política de los Estados Unidos Mexicanos, cuenten con las atribuciones necesarias para dar agilidad, prontitud, firmeza y precisión a los actos de aplicación de la ley específica que expida el Congreso de la Unión.

"REGLAS GENERALES ADMINISTRATIVAS. EL ARTÍCULO 36, FRACCIÓN I, INCISO A), DE LA LEY ADUANERA, VIGENTE EN MIL NOVECIENTOS NOVENTA Y SEIS, QUE AUTORIZA A LA SECRETARÍA DE HACIENDA Y CRÉDITO PÚBLICO PARA EXPEDIRLAS EN MATERIA DE IMPORTACIÓN, NO CONTRAVIENE LOS ARTÍCULOS 89, FRACCIÓN I, Y 92 DE LA CONSTITUCIÓN FEDERAL. Al establecer el artículo 36, fracción I, inciso a), de la Ley Aduanera, vigente en mil novecientos noventa y seis, la autorización al secretario de Hacienda y Crédito Público para expedir reglas generales que sirvan para precisar los requisitos y datos que deben reunir las fracturas comerciales de las mercancías que se importan a territorio nacional, cuando su valor de aduana se determine conforme al valor de la transacción y la cuantía de dichas mercancías exceda de la cantidad que también precisarán esas reglas, no contraviene lo dispuesto en los artículos 89, fracción I y 92 de la Constitución Política de los Estados Unidos Mexicanos. Lo anterior es así, pues con exclusión de las facultades conferidas al presidente de la República en los mencionados dispositivos constitucionales, el Congreso de la 
Unión puede expedir leyes donde autorice a los secretarios de Estado para dictar reglas técnico-operativas dentro del ámbito de su competencia; esto es, mientras el mencionado órgano legislativo no interfiera en la formación de los decretos, reglamentos, acuerdos u órdenes, que corresponde al titular del Poder Ejecutivo, puede otorgar directamente a las secretarías del Estado la atribución de emitir reglas operativas de observancia general dentro del campo de una ley específica."

"REGLAS GENERALES ADMINISTRATIVAS. LAS DICTADAS EN EJERCICIO DE UNA FACULTAD CONFERIDA POR LA LEY A UNA SECRETARÍA DE ESTADO, NO PUGNAN CON EL PRINCIPIO DE DISTRIBUCIÓN DE ATRIBUCIONES ENTRE LOS ÓRGANOS DEL PODER PÚBLICO. El primer párrafo del artículo 90 de la Constitución Política de los Estados Unidos Mexicanos dispone que "La administración pública federal será centralizada y paraestatal conforme a la ley orgánica que expida el Congreso, que distribuirá los negocios del orden administrativo de la Federación que estarán a cargo de las secretarías de Estado ... ". De lo anterior se deduce que las reglas generales administrativas dictadas en ejercicio de una facultad conferida por una ley expedida por el Congreso de la Unión a una secretaría de Estado constituyen una categoría de ordenamientos que no son de índole legislativa ni reglamentaria, sino que se trata de cuerpos normativos sobre aspectos técnicos y operativos para materias específicas, cuya existencia obedece a los contantes avances de la tecnología y al acelerado crecimiento de la administración pública, por lo que su expedición no pugna con el principio de distribución de atribuciones entre los diferentes órganos del poder público. Lo anterior es así, porque los reglamentos, decretos, acuerdos y órdenes, cuya expedición compete al Presidente de la República, en términos de los dispuesto en el artículo 92 de la propia Carta Magna, tienen diferente forma y materia que las reglas citadas, y mientras el Congreso de la Unión no interfiera en la formación de aquellos actos, puede conferir directamente a los secretarios de Estado la atribución de expedir reglas técnico-operativas dentro del campo de una ley específica; de manera que si el otorgamiento de atribuciones por la Norma Fundamental a los diferentes órganos gubernativos no puede extenderse analógicamente a otros supuestos distintos a los expresamente previstos en aquella, las reglas técnicas y operativas están fuera del ámbito exclusivo del titular del Poder ejecutivo, al gravitar dentro de la potesdad legislativa del Congreso de la Unión para autorizar su expedición mediante una ley a alguna o varias de la secretarias de Estado y departamentos administrativos, cuya distribución de competencias figura en la Ley Orgánica de la Administración Pública Federal, como en las demás leyes que le incumben al Congreso de la Unión." 
"REGLAS GENERALES ADMINISTRATIVAS EXPEDIDAS POR LOS SECRETARIOS DE ESTADO EN USO DE UNA FACULTAD AUTORIZADA POR EL CONGRESO DE LA UNIÓN. DIFERENCIAS CON LOS REGLAMENTOS, DECRETOS, ACUERDOS Y ÓRDENES DICTADAS POR EL PRESIDENTE DE LA REPÚBLICA. De lo dispuesto en el artículo 92 de la Constitución Política de los Estados Unidos Mexicanos, que establece la facultad del Presidente de la República para emitir reglamentos, decretos, acuerdos y órdenes, refrendados por el secretario de Estado o jefe del departamento administrativo a que el asunto corresponda, se infiere que tienen un contenido específico que los diferencia de las reglas generales administrativas, pues estas últimas son cuerpos normativos sobre aspectos técnicos y operativos para materias específicas, cuya existencia obedece a los constantes avances de la tecnología y al acelerado crecimiento de la administración pública; mientras que los reglamentos constituyen un conjunto de normas de carácter general para dar cumplimiento a las leyes; los decretos administrativos formalizan la expresión jurídica de la voluntad del ejecutivo en ejercicio de sus funciones, sobre casos concretos de los negocios públicos; las órdenes constituyen mandamientos del superior que deben ser obedecidas, ejecutadas y cumplidas por los inferiores jerárquicos y los acuerdos administrativos constituyen decisiones del titular del Poder Ejecutivo Federal dirigidas a los órganos subordinados, cuyos efectos se producen dentro de la propia estructura interna, que no atañen a los particulares o a otros sujetos de derecho que no tengan carácter de funcionarios o trabajadores al servicio del Estado".

El voto de los cuatro Ministros disidentes, nos dice:

No compartimos el sentido de las ejecutorias aprobadas por la mayoría del Tribunal Pleno, en los diversos amparos directos en revisión promovidos por Guillermo Alonso Cisneros, en atención a los razonamientos que se expresan a continuación.

El recurrente sostiene que la resolución del Tribunal Colegiado transgrede, entre otros, los artículos 16,73 y 89, Fracción I, de la Constitución Federal, toda vez que el legislador ordinario no puede delegar facultades reglamentarias y legislativas a una autoridad administrativa en este caso, a la Secretaría de Hacienda y Crédito Público, como lo hace a través del artículo 36, fracción I, inciso a), de la Ley Aduanera, el cual dispone lo siguiente:

"Artículo 36. Quienes importen o exporten mercancías están obligados a presentar ante la aduana, por conducto de agente o apoderado aduanal, un pedimento en la forma oficial aprobada por la Secretaría. En los casos de las mercancías sujetas a regulaciones y restricciones no arancelarias cuyo cumplimiento se demuestre a 
través de medios electrónicos, el pedimento deberá incluir la firma electrónica que demuestre el descargo total o parcial de esas regulaciones o restricciones. Dicho pedimento se deberá acompañar de:

\section{En importación:}

a) La factura comercial que reúna los requisitos y datos que mediante reglas establezca la Secretaría, cuando el valor en aduana de las mercancías se determine conforme al valor de transacción y el valor de dichas mercancías exceda de la cantidad que establezcan dichas reglas.

Con base en lo anterior, el recurrente sostiene que si la emisión de estas reglas generales es un modo de aplicación y ejecución de las leyes, como lo sostiene el Tribunal Colegiado que conoció del amparo directo, entonces tales reglas constituyen formalmente un reglamento, cuya expedición le corresponde de manera exclusiva al Presidente de la República, y materialmente una ley, por ser generales, impersonales, coercitivas y coactivas, situación que el mismo Tribunal Colegiado reconoce al decir que las mismas deberán cumplirse por los contribuyentes.

Continúa diciendo el recurrente que el Poder Legislativo Federal tiene reconocida su competencia en el artículo 73 de la Constitución Federal y en las demás disposiciones constitucionales, pero ninguna de ellas lo faculta para autorizar a la Secretaría de Hacienda y Crédito Público a emitir leyes, reglamentos complementos de disposiciones o propiamente las reglas generales que nos ocupan, salvo en los casos previstos en los artículos 29 y 131 de la Constitución Federal.

"De lo anterior se advierte que el tema substancial del presente asunto consiste en determinar si el Poder Legislativo cuenta con facultades constitucionales para autorizar a la Secretaría de Hacienda y Crédito Público a expedir "reglas", en las que establezca los requisitos y datos que deben contener las facturas que amparen a las mercancías que se importen a territorio nacional, sobre todo porque dichas reglas aparentemente tienen el carácter de reglamentos; por lo que esta minoría considera que lo primero que debió abordarse en las ejecutorias de mérito era la naturaleza de la facultad reglamentaria conferida al Presidente de la República, en términos del artículo 89, fracción I, constitucional, si esta facultad es delegable o no y posteriormente los alcances que puede tener el inciso a) de la fracción I del artículo 36 de la Ley Aduanera, pues en el supuesto de que a través de la ley impugnada realmente se confiera una facultad reglamentaria a la Secretaría de Hacienda y Crédito Público y la Constitución no autorice tal delegación, se actualizaría la transgresión constitucional que aduce el recurrente. 
De acuerdo con la doctrina y la jurisprudencia sostenida por este Alto Tribual en las más diversas épocas, el reglamento es el instrumento por medio del cual el titular del órgano crea situaciones jurídicas generales, abstractas, obligatorias, coercibles e impersonales, para desarrollar y detallar una ley en sentido formal y material.

Formalmente el reglamento es de naturaleza administrativa, sin embargo, materialmente comparte las características sustanciales de una ley, como son la generalidad, abstracción, obligatoriedad, impersonalidad y coercibilidad. Lo anterior quiere decir que en cuanto a su generalidad, tanto la ley como el reglamento permanecen después de su aplicación, esto es, deben aplicarse cuantas veces se dé el supuesto previsto, sin distinción de personas; en cuanto a su abstracción, tanto la ley como el reglamento se refieren a un número indeterminado e indeterminable de casos; por lo que se refiere a su obligatoriedad, la ley y el reglamento deben ser observados por todos los sujetos a los cuales van encaminados; en cuanto a su impersonalidad, se trata de disposiciones dirigidas a una pluralidad de personas, también indeterminadas o indeterminables; y finalmente, por lo que se refiere a su coercibilidad, ambos deben ser observados por los destinatarios incluso en contra de su voluntad, so pena, en muchos casos, de hacerse acreedores a una sanción.

En cuanto a sus diferencias con la ley, además de la ya apuntada, en cuanto a que proviene del órgano ejecutivo y no del legislativo, el reglamento siempre está supeditado al contenido de la ley, así como esta última lo está a la Constitución, sin que el reglamento pueda alterar su espíritu, ni el contenido y alcance de sus disposiciones. Por tal motivo, puede sostenerse que el reglamento crea o innova el derecho positivo, pero dentro del marco de la propia ley que le sirve de sustento.

A consideración de esta minoría, dentro de nuestro sistema constitucional la facultad reglamentaria le corresponde en forma exclusiva al Presidente de la República, según lo establecido por el artículo 89, fracción I, de la Constitución Federal:

\section{“Artículo 89, las facultades y obligaciones del Presidente, son las siguientes: \\ “ I. Promulgar y ejecutar las leyes que expida el Congreso de la Unión, proveyendo en la esfera administrativa a su exacta observancia.}

Lo anterior atiende a las siguientes razones:

a) Si bien es cierto nuestro sistema constitucional no admite un sistema rígido de división de poderes, sino al contrario, éste es flexible y prevé un sistema de pesos y contrapesos, con base en el cual un órgano formalmente ejecutivo, legislativo o judicial puede contar con facultades que materialmente corresponden a los otros dos poderes del Estado, dicho sistema se basa en el principio de facultades 
expresas o de legalidad ampliamente admitido por este Alto Tribunal; de tal suerte que sólo cuando el mismo texto constitucional, que establece las atribuciones de los tres órganos primarios del Estado, otorga facultades que materialmente le corresponden a otro poder, se estará en el caso de considerar legítimo el ejercicio de esta última facultad.

Por ende, en opinión de esta minoría, sólo la Norma suprema puede autorizar a un órgano del Estado para que expida normas generales que vinculen a los particulares, esto es, para realizar una función materialmente legislativa y si tal autorización no existe, por ejemplo, a favor de la administración pública federal, entonces cualquier acto administrativo expedido por ella que tenga contenido legislativo o reglamentario es inconstitucional.

b) Tampoco se advierte que el artículo 90, fracción I, de la Constitución Federal, autorice al titular del ejecutivo para delegar su facultad reglamentaria a favor de algún otro órgano del Estado, en particular, en la administración pública.

c) Lo anterior se comprende con mayor claridad si se toma en cuenta que la facultad reglamentaria constituye, desde un punto de vista material, una fracción legislativa que, de manera excepcional, se ha conferido al Presidente de la República.

En efecto, la facultad de expedir leyes le corresponde esencialmente al Congreso de la Unión, a quien le ha sido conferida esa función toda vez que se encuentra integrada por representantes de todo el pueblo para que, por su conducto, ejerza su soberanía, son elegidos democráticamente y por tanto, a través de ellos se da a sí mismo, con destinatario, las normas generales que habrán de obligarle.

El caso similar se presenta con el Presidente de la Republica, quien también ha sido electo democráticamente en un acto de soberanía popular y, por ende, el mismo Constituyente reconoce que puede emitir disposiciones de carácter general que vinculen a los gobernados; lo cual no se actualiza con los funcionarios de la administración pública y, por ende, no puede justificarse que los mismos expidan disposiciones de carácter general.

En consecuencia, el reglamento, en tanto es una norma de carácter general tendiente a facilitar en la esfera administrativa el cumplimiento y exacta aplicación de la ley, sólo puede ser expedido por el Presidente de la República. 
Asimismo, se advierte que la facultad reglamentaria conferida al Ejecutivo no deriva de ninguna delegación del legislador ordinario, sino que se encuentra su fundamento directamente en la Constitución.

El sustento de carácter lógico o práctico del reglamento se explica por la imposibilidad de que el órgano legislativo pueda prever todas las contingencias en que haya de enfrentar la autoridad en la aplicación de la ley, además de que en muchas ocasiones el proceso legislativo no puede tener la rapidez que requiere la evolución y desenvolvimiento de la materia que regula la misma norma. En este aspecto, la Constitución confiere única y exclusivamente al Ejecutivo facultades para complementar a través de normas generales la ordenación que la propia ley establece y, a su vez, provee para el debido ejercicio de las funciones que le encomienda la misma norma.

En este aspecto, conviene destacar que el constituyente no limitó de manera alguna la materia sobre la cual puede versar un reglamento, esto es, no existe mayor impedimento para que el Poder ejecutivo pueda dictar disposiciones de contenido técnico-operativo en forma de reglamentos; de tal suerte que aún cuando las reglas generales que dicta la administración pública tengan ese contenido, no por ello las convierte en normas jurídicas sui géneris, distintas de la ley o del reglamento.

Una vez establecida la naturaleza y características del reglamento, el segundo paso consiste en determinar si el artículo 36, fracción I, inciso a) de la Ley Aduanera, faculta a una autoridad administrativa diferente del Poder Ejecutivo Federal a expedir reglamentos y por ende, lo hace inconstitucional.

Del contenido del citado precepto legal, se advierte que la norma deja expresamente una laguna en cuanto a los requisitos y datos que debe contener la factura que acompañe al pedimento de importación, facultado a la Secretaria de Hacienda y Crédito Público para que colme ese vacío a través de reglas. Lo anterior nos lleva a concluir que, independientemente de la denominación que se les dé a esas disposiciones de carácter legal, lo que está haciendo es integrar el derecho positivo dentro del marco de la misma ley en sentido formal y material que le sirve de sustento, lo cual, visto desde un punto de vista material, convierte a tales normas generales en auténticos reglamentos.

Lo anterior queda más claro si se hacen las siguientes reflexiones:

a) A través del contenido de tales reglas, se crean situaciones jurídicas generales, abstractas, impersonales, obligatorias y coercibles. 
Esto es así porque las reglas en cuestión se encuentran dirigidas a todos los gobernados que pretendan importar mercancías a territorio nacional, al tenor del artículo 36, fracción I, inciso a), de la Ley Aduanera, sin que se agoten con el primer acto de aplicación (característica de generalidad); abarcan a todos los posibles casos concretos que encuadren en el supuesto previsto por la ley que vienen a integrar (característica de abstracción); sin que pueda decirse que la normatividad administrativas tenga un destinatario fijo (característica de impersonalidad); son de observancia obligatoria para todos los importadores en tanto que les impone el deber de que la factura comercial contenga los requisitos que en ella se prevean (característica de obligatoriedad); e, inclusive, ya desde un plano hipotético pero no por ello imposible, las misma pueden prever una sanción para el caso de incumplimiento, como sucede con muchas de ellas (característica de coercibilidad).

b) A través de estas reglas generales, se desarrolla y detalla una ley en sentido formal y material. En efecto, el artículo 36, fracción I, inciso a) de la Ley Aduanera, es una norma general expedida por el Congreso de la Unión para regular el despacho aduanero, y mediante la normatividad administrativa en estudio se consigue pormenorizar su texto, para señalar los requisitos que debe reunir la factura que ampara a la mercancía que se pretende importar; sin que por ello se rebase el contenido o alcance de las disposiciones contenidas en la misma ley.

c) En consecuencia, a través de esta regla general se crea, se innova o integra el derecho positivo, dentro del marco de la propia ley que le sirve de sustento.

d) Asimismo, a través de esta disposición general se facilita en la esfera administrativa el cumplimiento y exacta aplicación de la Ley Aduanera, al señalar cuáles son los requisitos y detalles que la autoridad administrativa debe apreciar en las facturas de las mercancías a importar, a fin de considerar que en cada caso concreto se ha cumplido o no con esta etapa del derecho aduanero.

e) En tales reglas generales se busca establecer requisitos y datos mínimos de un documento, mismo que por su carácter específico no resultaría conveniente prever en la propia ley de la materia, es decir, que no resultaría eficaz que el Congreso de la Unión se ocupara en detallar las características que debe reunir una factura, cuando éstas dependen de los usos comerciales y requerimientos mercantiles que imperen en un momento determinado, resultando en este aspecto más sencillo que un órgano unipersonal se aboque a su especificación.

Por lo anterior, se advierte que las reglas a las cuales se refiere el artículo 36 , fracción I, inciso a), de la Ley Aduanera, tiene todas las características de un 
reglamento, visto desde el punto de vista estrictamente material, de tal suerte que lo único que realmente distingue a las reglas generales que nos ocupan, del reglamento, son los siguientes aspectos formales:

- Se trata de una resolución general dictada por la administración pública centralizada, particularmente por la Secretaria de Hacienda y Crédito Público, y no por el Presidente de la República, y

. Su fundamento se encuentra previsto en una ley en sentido formal y material y no en la Constitución General.

Lo cual realmente agravia a los particulares, pues al tratarse de disposiciones que pueden ser dictadas por la pluralidad de entidades que integran la administración pública, con base en una autorización del poder legislativo, pueden multiplicarse en número y regular tan diversas materias, que lo único que consigan es privar de seguridad jurídica al gobierno al cual conminan.

Por otro lado, en opinión de esta minoría, las ejecutorias dictadas en el presente asunto de alguna manera reconocen que las reglas de carácter general que expide la Secretaría de Hacienda y Crédito Público son auténticos reglamentos, lo cual se infiere del análisis el siguiente pronunciamiento:

"Lo anterior se justifica en la medida que el Poder Legislativo no suele ocuparse de los detalles técnico-operativos que surgen en el funcionamiento de la Administración Pública, de ahí que resulte apropiado que los Secretarios de Estado como integrante de la Administración Pública Federal, conforme con lo dispuesto por el artículo 90 constitucional, cuenten con las atribuciones necesarias para dar agilidad, prontitud, firmeza y precisión a los actos de aplicación de la ley específica que expida el Congreso de la Unión."

Y según quedó expuesto con anterioridad, una característica esencial del reglamento es precisamente la de dar agilidad, prontitud, firmeza y precisión a los actos de aplicación de la ley que expida el Congreso de la Unión.

En este orden de ideas, si la facultad reglamentaria le corresponde de manera exclusiva al Presidente de la República y no existe ninguna disposición constitucional que lo faculte para cederla o transmitirla a la administración pública, ni tampoco un precepto expreso de la Norma Suprema que autorice a dicha administración a expedir reglas con contenido legislativo, entonces esta última no puede arrogarse esa función, de tal suerte que en el caso que nos ocupa, las reglas generales a las que se refiere el artículo 36, fracción I, inciso a), de la Ley Aduanera, son inconstitucionales. 
Para reforzar lo anterior, es necesario pasar a un tercer aspecto, consistente en determinar si el Congreso de la Unión realmente tiene facultades constitucionales para autorizar a la Secretaría de Hacienda y Crédito Pública a que expida una normatividad con las características materiales de un reglamento, el cual, como se vio anteriormente, corresponde emitir de manera exclusiva al Presidente de la República.

El artículo 73 de la Constitución Federal establece la competencia del Congreso de la Unión para legislar sobre las materias en él establecidas y, particularmente la fracción X constituye el fundamento para la expedición de la Ley Aduanera:

"Articulo 73.- El Congreso tiene facultad:

$\cdots$

X. Para legislar en toda la República sobre hidrocarburos, minería, industria cinematográfica, comercio, juego con apuestas y sorteos, intermediación y servicios financieros, energía eléctrica y nuclear, y para expedir las leyes del trabajo reglamentarias del artículo 123.

..."

Sin que se aprecie de dicho numeral, ni de ninguna otra posición de la Constitución General, que el Congreso esté facultado para atribuir a la Secretaría de Hacienda y Crédito Público o alguna otra dependencia estatal la creación de un complemento normativo a la Ley Aduanera, como lo son las reglas generales que nos ocupan.

Lo anterior es comprensible porque, como se ha visto, conforme al régimen previsto en el artículo 49 constitucional, sólo tiene facultades para legislar el poder Legislativo y excepcionalmente el Ejecutivo a través de reglamentos, facultades que únicamente pueden ser ejercidas por estos poderes, siendo de reconocido derecho que en la Constitución no existe una disposición que faculte a tales órganos del Estado a delegar sus funciones en alguna otra persona o entidad, por lo que si el Poder Legislativo no puede ceder su propia facultad legislativa, por mayoría de razón tampoco puede delegar una atribución que no le corresponde como lo es la reglamentaria.

Por otro lado, es de reconocido derecho que a los órganos secundarios de la administración pública les corresponde únicamente aplicar y, en su caso, vigilar el exacto cumplimiento de la ley o el reglamento en los casos concretos que se les presenten dentro de su esfera de atribuciones, a través de actos administrativos que, como tales, no se poseen los elementos de generalidad, abstracción e impersonalidad de los que gozan la ley o el reglamento. Por lo anterior, en la materia que nos ocupa, la autoridad administrativa a quien le compete el despacho aduanero no puede crear, innovar o integrar propiamente el derecho positivo, pues 
ello le corresponde exclusivamente al Presidente de la República, con base en la fracción I del artículo 89 de la Constitución Federal.

Sostener lo contrario, es decir, que la administración pública centralizada tiene facultades para expedir normas generales que reglamenten a la Ley Aduanera, estaría dando por supuesto que cualquier órgano derivado del Estado podría asumir, aunque sea materialmente hablando, alguna de las facultades que conforme a la Constitución General les corresponde expresamente y de manera exclusiva a los órganos primarios del Estado.

En consecuencia, si el Congreso de la Unión no cuenta con atribuciones constitucionales para delegar en favor de la Secretaría de Hacienda y Crédito Público facultades reglamentarias y, en el caso a estudio, el artículo 36, fracción I, inciso a) de la Ley Aduanera, autoriza a la citada dependencia a expedir normas generales que detallen o complementen el contenido de la misma ley, a fin de fijar

Los requisitos y datos de las facturas comerciales que amparen a las mercancías objeto de importación, se concluye que, en este aspecto, el precepto legal impugnado es inconstitucional.

Por último, aunque lo que a continuación se expresa no sustenta propiamente la inconstitucionalidad de la norma en estudio, resulta ilustrativo destacar que de la lectura del artículo 37 de la Ley Aduanera se desprende que el Legislador ha considerado que es a través del reglamento como se debe detallar el contenido de la ley en sentido formal y material, para que así, en supuestos similares al que ahora se estudia, se establezcan en el Reglamento los requisitos que deben contener las facturas que se acompañen a los pedimentos de importación consolidados. Se transcriben a continuación tanto el citado artículo 37 de la Ley Aduanera como el artículo 58 de su reglamento que lo viene a detallar:

“Artículo 37. Quienes exporten mercancías podrán presentar ante la aduana, por conducto de agente $o$ apoderado aduanal, un solo pedimento que ampare diversas operaciones de un solo exportador, al que se denominara pedimento consolidado.

Tratándose de las maquiladoras y las empresas con programas de exportación autorizados por la Secretaría de Comercio y Fomento Industrial, también podrán optar por promover el despacho aduanero de las mercancías mediante pedimento consolidado para su importación.

Quienes ejerzan las opciones a que se refiere este artículo, deberán cumplir con los requisitos que para tal efecto establezca el Reglamento. 
"Artículo 58. Para efecto del artículo 37 de la Ley, quienes opten por promover el despacho aduanero de mercancías mediante pedimento consolidado, deberán cumplir con lo siguiente:

I...

II. Presentar las facturas, que deberán contener los siguientes datos:

a)Nombre o razón social y Registro Federal de Contribuyentes de quien promueve el despacho;

b)Fecha y número de la factura;

c)Descripción, cantidad y valor de las mercancías;

d)Datos del vehículo que transporta la mercancía.

En ningún caso una factura podrá amparar varios vehículos;

e) Número de pedimento bajo el cual se consolidan las mercancías;

f) Código de barras con los datos que establezca la Secretaría;

g) Nombre, firma, número de patente $o$ autorización del agente $o$ apoderado aduanal, respectivamente, que presentará el pedimento al despacho, y

h) Número de identificación de los candados oficiales.

Tratándose de exportaciones, éstos podrán presentar, en lugar de las facturas, cualquier otro documento que contenga los datos referidos;

..."

De donde se desprende que no es menester autorizar a las dependencias del Ejecutivo Federal para que expidan disposiciones de carácter general que detallen el contenido de la ley, pues bien puede hacerse a través de un reglamento que con fundamento en el artículo 89, fracción I, de la Constitución Federal, expida el Presidente de la República, sin que este último tenga mayor dificultad técnica $u$ operativa para ello.

Por las razones antes expuestas, esta minoría no comparte el sentido de las ejecutorias aprobadas por la mayoría del Tribunal Pleno."

c)Sin embargo, el Pleno de la Suprema Corte de Justicia de la Nación, en su Tesis

P. IV/2004, en el amparo en Revisión 1532/2003, resuelto el 11 de mayo de 2004, sostuvo lo siguiente.

RESOLUCIÓN MISCELÁNEA FISCAL. LAS REGLAS QUE CONTIENE PUEDAN LLEGAR A ESTABLECER OBLIGACIONES A LOS CONTRIBUYENTES, YA QUE NO CONSTITUYEN CRITERIOS DE INTERPRETACIÓN SINO DISPOSICIONES DE OBSERVANCIA GENERAL.- 
De los artículos 33, párrafo penúltimo y 35 del Código Fiscal de la Federación se advierte que la atribución conferida a diversas autoridades fiscales para dar a conocer los criterios internos que deben seguirse en la aplicación de las normas tributarias, se refiere a las interpretaciones que esas autoridades realicen de cualquier disposición de observancia general que incida en el ámbito fiscal, bien sea una ley, un reglamento o una regla general administrativa, por lo que, por su propia naturaleza, no pueden generar obligación alguna a los gobernados sino, en todo caso, ser ilustrativas sobre el alcance de dichas normas y en caso de publicarse en el Diario Oficial de la Federación, otorgarán derechos a los contribuyentes. En cambio, las disposiciones de observancia general cuya emisión y publicación se rigen, respectivamente, por lo dispuesto en los artículos 14, fracción III, del Código Fiscal de la Federación, tienen como finalidad precisar la regulación establecida en las leyes y reglamentos fiscales expedidos por el Congreso de la Unión y el Presidente de la República con el fin de lograr su eficaz aplicación y están sujetas a principios que tutelan la seguridad jurídica de los gobernados, entre otros, los de reserva y primacía de la ley, por lo que deben ceñirse a lo previsto en el acto formal y materialmente legislativo que habita su emisión. En tal virtud, al tratarse de actos de diversa naturaleza no existe razón alguna para considerar que las reglas agrupadas en la Resolución Miscelánea Fiscal se rigen por los mencionados artículos 33, párrafo penúltimo y 35 , ya que éstos se refieren exclusivamente a criterios interpretativos que sostengan las autoridades fiscales, los que en ningún momento serán obligatorios para los gobernados, a diferencia de las disposiciones de observancia general que emita el Presidente del Servicio se Administración Tributaria, las cuales son de cumplimiento obligatorio para los gobernados, sin menoscabo de que alguna de ellas con motivo de una sentencia dictada en algún medio de defensa que prevé el orden jurídico nacional, puede perder sus efectos, total o parcialmente, al no ceñirse a los referidos principios y, en su caso, a las condiciones que establezca el legislador para su dictado.- Visible en el SJFyG, tomo XX, Pleno, Salas y Acciones de Inconstitucionalidad, septiembre de 2004, página 15-.

d)Pero la Segunda Sala de la Suprema Corte de Justicia de la Nación, en su jurisprudencia $2^{\mathrm{a}} . / \mathrm{J}$. 07/2004, contradice la tesis del Pleno antes transcrito, al sostenerse:

COMERCIO EXTERIOR. LAS REGLAS GENERALES ADMINISTRATIVAS EN ESA MATERIA PUEDEN REGULAR OBLIGACIONES DE LOS GOBERNADOS, SIEMPRE Y CUANDO RESPETEN LOS PRINCIPIOS DE RESERVA DE LEY Y RESERVA REGLAMENTARIA, Y SE APEGUEN AL CONTEXTO LEGAL $Y$ REGLAMENTARIO QUE RIGE SU EMISIÓN.- Las referidas reglas generales las 
emite el Presidente del Servicio de Administración Tributaria con base en los artículos 14, fracción III, de la Ley del Servicio de Administración Tributaria y 33 , fracción I, inciso g), del Código Fiscal de la Federación, los que a su vez se sustentan en los diversos 73, fracción XXX y 90 de la Constitución Política de los Estados Unidos Mexicanos, por lo que no existe impedimento constitucional para que mediante esas reglas se regulen determinadas obligaciones de los gobernados, siempre y cuando no incidan en una materia sujeta a reserva de ley y no rebasen el contexto legal y reglamentario que rige su emisión, aunado a que aquéllas no se rigen por lo previsto en los artículos 33, penúltimo párrafo y 35 del Código Fiscal de la Federación, ya que éstos se refieren a los criterios internos que deben seguirse en la aplicación de las normas que inciden en el ámbito fiscal, bien sea una ley, un reglamento o una regla general administrativa, por lo que por su propia naturaleza no pueden generar obligación alguna a los gobiernos sino, en todo caso, ser ilustrativos sobre el alcance de alguna disposición de observancia general, y de publicarse en el Diario Oficial de la Federación, otorgar derechos a los contribuyentes, a diferencia de las citadas reglas generales, que son de cumplimiento obligatorio para los gobiernos, sin menoscabo de que alguna de ellas, en virtud de sentencia dictada en algún medio de defensa jurisdiccional establecido por el orden jurídico nacional, pueda perder sus efectos total o parcialmente, por no respetar los mencionados principios que rigen su emisión. SJFyG. Pleno, Salas y Acciones de Inconstitucionalidad, septiembre de 2004, página 109.

\section{Conclusión.}

Las reglas administrativas devienen de criterios de interpretación de la autoridad fiscal que, una vez publicadas en el diario Oficial de la Federación, pueden otorgar derecho pero no imponer obligaciones o requisitos a los contribuyentes en exceso de las que contienen las leyes, o, en otras palabras, la regla Administrativa nos debe aclarar lo que dice una disposición pero sin excederse del contenido de las palabras que empleó el legislador o el Ejecutivo Federal, nunca ir más allá de lo que contiene la disposición que se interpreta por la autoridad administrativa. 